\title{
Ressenya
}

\section{Vilagrasa, Albert (ed.) (2018). A punt 1. Curs de català. Llibre de l'alumne. Publicacions de l'Abadia de Montserrat}

\author{
Isabel Cama Llordés \\ Consorci per a la Normalització Lingüística de Terrassa i Rubí \\ icama@cpnl.cat
}

Rebut: 6 de maig del 2020

Acceptat: 30 de juny del 2020

Ens plau poder parlar d'una novetat: el manual A punt 1. Curs de català. Llibre de l'alumne, publicat el juliol de 2018 per Publicacions de l'Abadia de Montserrat. Inclou un CD amb àudios, pensat per a classes presencials de català per a un alumnat adolescent $\mathrm{i}$ adult que vol assolir el nivell A1 de llengua catalana del MECR. Els autors que han elaborat aquest llibre són Gemma Verdés Prieto, Joana Álvarez Verger, Marilisa Birello, Marta Mas Prats i Montserrat Pérez Ventayol, amb la coordinació d'Albert Vilagrasa Grandia. El manual de l'alumne està complementat amb una guia per al professor, A punt 1. Curs de català. Llibre del professor, elaborada per Alba García Travé i Martina Zanolli i coordinada per Albert Vilagrasa Grandia. També s'ha publicat un llibre d'exercicis amb el mateix títol. És evident que l'edició del manual de l'alumne, de qualitat, en paper gruixut i fotografies en color, ha passat una bona revisió.

Al manual queda molt ben reflectida l'experiència de l'equip de professionals en l'ensenyament-aprenentatge de llengües dedicat a adolescents i adults. El mètode funciona i, sens dubte, ho fa perquè no solament s'ha elaborat a partir de la teoria de la didàctica, sinó perquè al currículum dels autors hi ha hores i hores de feina com a professors de català a l'aula, i en l'aprenentatge i ensenyament de diverses llengües. Es tracta d'autors que han treballat en entitats molt diferents i amb un llarg recorregut en l'ensenyament de llengües: Escoles Oficials d'Idiomes, diverses universitats del Principat i el Consorci per a la Normalització Lingüística (CPNL). Alguns d'aquests autors ja havien publicat material de renom per a l'ensenyament de la llengua catalana, com ara els manuals Veus. Curs de català. No podem menystenir de cap manera que, en aquest equip, també hi ha expertesa en recerca en didàctica de la llengua.

El que podem dir sobre l'A punt 1 es basa en l'ús que en fem al Consorci per a la Normalització Lingüística, concretament a Terrassa i Rubí. Cal tenir en compte, per això, que tenim un perfil d'alumnat que pot ser molt diferent d'altres àmbits (com ara les EOI o les universitats): inclou alumnes amb capacitats lectoescriptores de tots els nivells i realitats culturals molt diverses. Aquest manual en principi està pensat per al nivell $\mathrm{A} 1$, però al nostre centre el fem servir per al Bàsic 1 i Bàsic 2, de 45 hores cada un, que es troben a mig camí entre l'A1 i l'A2. Tot i que en altres entitats, amb un alumnat més homogeni, amb formació superior, el manual podria completar-se amb menys hores de classe. Nosaltres també fem servir l'A punt 2 per als nivells Bàsic 3 (en què s'assoleix el nivell A2 del MECR) i l'Elemental 1, també de 45 hores cadascun.

Volem destacar l'enfocament de l'A punt, comunicatiu i basat en l'acció, perquè representa una novetat en el mercat de manuals per a l'ensenyament de la llengua catalana. Podem dir que 
l'hem acollit molt bé perquè lliga totalment amb la filosofia del CPNL. S'adiu amb el nostre sistema d'ensenyament basat en tasques en què es prioritza que l'alumnat pugui fer servir la llengua en la seva vida quotidiana des del primer dia i, per tant, dona prioritat a l'adquisició de les competències orals en aquesta primera etapa d'aprenentatge. Així, en cadascuna de les nou unitats didàctiques del llibre, a través de quatre etapes que permeten treballar aspectes lèxics, gramaticals i fonètics essencials, es condueix l'alumne fins a l'acompliment d'una tasca en una situació versemblant com la que es trobaria fora de l'aula, a la vida real i, finalment, se li proposa autoavaluar-se. Alhora, les tasques proposades estan pensades per fomentar el treball col.laboratiu i la interacció oral i escrita a l'aula, amb textos que reflecteixen les característiques de la societat actual (en forma de xats i fòrums); fotografies i il-lustracions, indispensables per a la comprensió de conceptes, i títols suggeridors per incitar a la participació. Totes aquestes característiques fomenten la motivació, un aspecte indispensable per a l'aprenentatge-ensenyament d'una llengua addicional. La gramàtica no s'hi descuida gens, a través de píndoles que proposen la reflexió metalingüística i la comprensió lògica del funcionament de la llengua, i d'un resum gramatical al final de cada unitat.

Pel que fa a l'estructura interna de les unitats, estan plantejades de manera reversible; és a dir, que es poden treballar en diferent ordre sense que perdin el sentit. També estan dissenyades de manera oberta i flexible, per tant, no és necessari treballar totes les tasques proposades per arribar a dur a terme la tasca final. Això facilita molt la programació de les sessions per al professor, ja que li permet adaptar les classes a les necessitats de grups heterogenis, tant pel que fa al grau de dificultat exigit a l'alumne (que en el cas de la nostra entitat pot tenir competències lectoescriptores baixíssimes), com a la quantitat de continguts. Aquest estil de treball lliure també és inspirador per al professor novell i poc avesat al treball basat en tasques, perquè li permet dissenyar les seves pròpies dinàmiques.

Si ens fixem en els detalls de l'edició, veiem que no són gratuïts. Algunes característiques visuals ajuden el professor a treballar els aspectes importants del text. Així, les expressions marcades en groc en cada text són estructures a què cal fer atenció. Els símbols que trobem al costat del número de cada activitat ens indiquen quin tipus d'activitat es proposa (àudio, reflexió metalingüística...).

El manual inclou altres elements que són indispensables per al treball individual de l'alumne (amb formació secundària o universitària) i que permeten la consulta de continguts fora de l'aula, com ara les transcripcions dels àudios i el resum gramatical que hi ha al final del llibre. D'altra banda, al manual hi ha un mapa dels Països Catalans i un apartat anomenat "Calendari cultural", que introdueixen continguts de civilització d'una manera atractiva i adaptada al nivell lingüístic de l'alumne. Si hi afegim el llibre d'exercicis, tenim encara més material per a l'alumnat amb formació secundària i universitària.

Si comparem l'A punt amb els manuals d'ensenyament-aprenentatge que tenen més suport econòmic, els de llengua anglesa, lògicament som conscients que la guia didàctica podria incloure material fotocopiable, en forma de jocs, targetes, cançons i, fins i tot, un DVD amb vídeos; és a dir, propostes alternatives que els professors fabriquem als centres per enriquir certs moments a l'aula. Però, per la resta, aquest manual s'hi acosta molt i qui sap si arribarà al mateix nivell en properes actualitzacions. Hem d'aspirar al millor en aquest sentit.

En resum, A punt 1. Curs de català ha estat oli en un llum al nostre Servei de Català. És un suport excel-lent per al nostre professorat i representa un gran canvi. Necessitàvem un material centrat en l'enfocament comunicatiu basat en l'acció. Fins ara les nostres programacions eren dossiers fabricats, editats i actualitzats de manera artesana, sense el suport del món editorial. Esperem que l'editorial pugui continuar impulsant aquesta eina, actualitzant-la i millorant-la, i que continuï tenint el suport de tan bons especialistes. 